\title{
Escravos sem senhores não existem
}

\author{
Marcelo Santos Matheus* \\ Manolo Florentino**
}

READ, Ian. The hierarchies of slavery in Santos, Brazil, 1822-1888. Stanford: Stanford University Press, 2012.

A exagerada ênfase no protagonismo dos cativos pode levar o historiador a elidir a obviedade contida na afirmação de que, tal como não há senhor sem escravo, tampouco há escravo sem senhor. A radicalização desse ponto de vista talvez tenha alcançado o auge na década de 1970, quando se chegou a postular que nas plantations do sul dos Estados Unidos conviviam duas culturas paralelas e estanques - a escrava e a senhorial. Entretanto, em história, como na dura escola da vida, ninguém se encontra imune a recaídas, e a nefasta essencialização da categoria "negro" pode representar, hoje, o caminho mais curto para recidivas.

Em The hierarchies of slavery o historiador norte-americano Ian Read busca recolocar o problema em seu justo lugar. Analisa os cativos no município de Santos entre 1822 e 1888, sustentando sem hesitação ter sido a posição social do senhor, definida pelo status e condiçóes econômicas (além das demográficas), o fator determinante a reger a diferenciação entre os próprios escravos. Não se trata de desprovê-los de iniciativas desesperadas ou minuciosamente pensadas, capazes de moldar muitos destinos para melhor, mas sim de buscar o ponto de partida metodológico para melhor entendê-las.
Provido de sólido embasamento weberiano, o autor crê que compreender o fenômeno da mobilidade social implica, antes, a identificaçáo dos elementos em função dos quais se estratifica determinada sociedade como um todo. Só a partir de semelhante procedimento seria possível compreender os mecanismos de reprodução da diferenciação que apartava os cativos entre si. Foge, pois, do engessamento característico ao uso de categorias demasiado abrangentes, as quais, por isso, pouco contribuiriam para a análise. Eis o motivo pelo qual descarta a noçáo de classe, por exemplo, pouco útil sobretudo para estabelecer a distinção, na base da pirâmide, entre os incontáveis milhares de miseráveis livres e libertos, por um lado, e os escravos, pelo outro. Ponto para Read, sobretudo por debruçar-se sobre um tipo de sociedade que se reproduzia no tempo por meio da própria diferenciação social entre os seus pares livres, como há muito ensinou Moses Finley.

Ao circunscrever a análise a uma localidade pequena como a cidade do litoral paulista ao longo do período imperial, o autor pôde apreender as mudanças ocorridas no escravismo Oitocentista em espaço semelhante à maioria das regiôes brasileiras de escravidão periférica, onde a escravaria se concentrava em áreas semiurbanas - unidades agrourbanas, para utilizar uma noção cara aos escritos de Richard Morse sobre a cidade colonial hispano-americana. Tal escolha permitiu a Ian

\footnotetext{
* Mestre em história pela Universidade do Vale do Rio dos Sinos, doutorando em história social pela Universidade Federal do Rio de Janeiro. Rio de Janeiro, RJ, Brasil. E-mail: msmportugues@hotmail.com.

** Doutor em história pela Universidade Federal Fluminense, professor associado da Universidade Federal do Rio de Janeiro, bolsista de produtividade científica do CNPq, nível 1A. Rio de Janeiro, RJ, Brasil. E-mail: mgflorentino@gmail.com.
} 
Read fartar-se da prosopografia para cruzar fontes variadas. Conquanto se trate de uma técnica consagrada pela chamada "micro-história italiana", o autor não dialoga diretamente com nenhum dos ícones dessa vertente historiográfica. Sintoma, talvez, da secular distância entre a cultura acadêmica anglo-saxã e a latina, o que não deixa de ser um problema... para italianos e franceses.

O trabalho envereda pela exploração de listas nominativas de habitantes, cartas de alforrias, manuscritos da Santa Casa de Misericórdia local, registros eclesiásticos, jornais, revistas, almanaques, documentação cartorária e demais. Em razão das boas condiçôes em que se encontram os arquivos santistas, Read conseguiu cruzar mais de vinte tipos de registros afeitos à posopografia. Ao final, cerca de 2 mil senhores e trezentos escravos puderam ser identificados em pelo menos duas fontes. A densidade do material resultante levou-o a utilizar-se da network analysis por meio de ferramentas da informática que auxiliam na construção de redes — o Pajek, por exemplo.

Na primeira parte do livro — "Senhores e seus escravos" - , o autor realiza um primoroso trabalho com as listas nominativas de habitantes, deitando um olhar socioespacial sobre o município, através de bairros e fogos, desde as zonas de maior concentração de senhores até as ausentes de cativos, pesando e analisando as suas características. O resultado é bastante interessante e corrobora aquilo que alguns pesquisadores brasileiros têm encontrado em regióes similares: o predomínio de pequenos plantéis, combinado à disseminação da propriedade escrava pelos diferentes estratos sociais, i.e., um alto grau de adesáo social à escravidão antes de 1850. Para além da posse de cativos, os indivíduos livres eram hierarquizados por benfeitorias realizadas nas fazendas (moinhos, destilarias etc.), pelas ferramentas destinadas à produção de alimentos ou, mesmo, por deterem pequenos barcos e até de redes de pescar - peculiaridades de uma regiáo litorânea.

A seguir, constata, para os bairros de maiores escravarias, terem os senhores geralmente chamados "brancos" compartilhado profissóes tais como comerciantes e fazendeiros. Onde predominavam as pequenas escravarias, ao revés, havia mais senhores classificados como "de cor", em uma clara sugestão de que a referência à cor por vezes remetia mais à "qualidade social" do que propriamente ao tônus da pele do indivíduo, noves fora nossa peculiar miscigenação, é claro. Nas zonas habitadas pelos maiores proprietários também havia mais matrimônios escravos sancionados pela Igreja. Contudo, em outro bom momento do livro, Ian Read ressalta que as crianças encontravam-se disseminadas pelos diversos tipos de escravarias, dado a questionar o peso da legitimidade para a família cativa, para náo falar da possibilidade de que a obtenção de altos graus de reprodução endógena das escravarias garantisse o grosso da reprodução do cativeiro santista. De fato, urge superar a clássica ideia de que, após o fim do tráfico atlântico (1850), o nordeste brasileiro conseguia atender, em escala, a demanda do sudeste (insistir em uma escravidão absolutamente infensa a graus razoáveis de reprodução natural dos cativos - ainda que combinada à aquisição de escravos através do mercado - apenas reitera a facilidade contida na associação entre as plantagens e verdadeiros campos de concentração).

Procedimento algo raro entre os pesquisadores nacionais - embora algo comum entre os historiadores hispano-americanos —, a utilização da categoria "bairro" ou "vizinhança" mostrou-se altamente operativa para o autor. A partir dela foi detectada certa homogeneidade entre os senhores dos mesmos perímetros espaciais, permitindo identificar aspectos da vida dos cativos em diferentes vizinhanças - notadamente, aferir a representatividade da família escrava, das ocupações dos cativos, das puniçóes que recebiam, do cuidado com a saúde, formas de alforria e taxas de fuga, abordados na segunda parte do livro. $\mathrm{O}$ uso do conceito e da ferramenta das networks igualmente possibilitou verificar que algumas redes extrapolavam em muito o estrato social dos indivíduos. Tal foi o caso da liberta africana Tereza de Jesus Januária, ligada a seis potentados locais, circunstância que lhe permitia desfrutar de melhores condiçóes de vida. Desenha-se, pois, uma sociedade dividida em camadas horizontais, cujos mem- 
bros compartilhavam, entretanto, laços verticais que as seccionavam.

Destaque para a atenção dada às mudanças ocorridas nos padróes econômicos e demográficos dos senhores e no mercado local de escravos. Ian Read demonstra que, ao longo do século XIX, Santos possuía, em números absolutos, uma população cativa mais ou menos estável, embora, relativamente falando, ela tenha diminuído consideravelmente devido ao afluxo de estrangeiros atraídos por oportunidades de emprego no porto. Detecta igualmente que na segunda metade do Oitocentos ocorreu uma pronunciada concentração da propriedade escrava, movimento que vem sendo revisto por algumas pesquisas e reiterado por outras. Para quem estuda o abolicionismo, fica a hipótese: em casos como o de Santos, à concentração da estrutura de posse não poderia haver correspondido um menor grau de adesão das camadas médias e mesmo dos pobres à escravidão?

Ao final da primeira parte, composta de quatro capítulos, o autor analisa o tráfico de escravos em Santos. É quando mapeia duas redes mercantis, das quais dependiam os senhores para vender, comprar ou alugar cativos. Read dá maior ênfase a estas redes locais de comércio do que aos grandes comerciantes, os quais se encontravam por certo imersos nessas networks, cujas feiçóes eram no entanto determinadas em grande medida por relaçóes de vizinhança. Partindo dessa pista, descobre-se que, em geral, um escravo era transacionado entre vizinhos (ou entre membros de uma mesma rede de relaçóes), e não com as regióes produtoras de café, onde os cativos tinham um valor maior. Diminuir os riscos do negócio e privilegiar as relaçóes pessoais eram parte do cálculo senhorial e, pois, do próprio mercado local.

A segunda parte do livro - "Escravos e seus senhores" - , também composta por quatro capítulos, centra a atençáo sobre os cativos, abordando a família, condiçôes de trabalho, puniçôes e os cuidados médicos, além do acesso à liberdade mediante alforrias e fugas. Seria este o rol de elementos que, secundariamente, definia a hierarquia entre os cativos - o primeiro e mais importante, já mencionamos, era o status senhorial. Escravos de senhores que desfrutavam de uma melhor posição social tinham mais chances de constituírem famílias mais estáveis - Ian Read percebeu que nos bairros onde viviam os senhores com mais cativos, estes tendiam a reaparecer em censos nominais de diferentes anos, indício de estabilidade dos agregados parentais. Destoando de trabalhos que procuram estabelecer, exclusivamente a partir das características dos próprios escravos, padróes e tendências relativas ao matrimônio perante a Igreja, Ian Read desenvolve melhor a ideia de que a riqueza, a posição social dos senhores e o lugar em que estes moravam eram mais importantes para determinar o sancionamento eclesiástico do que o sexo ou lugar de nascimento dos cativos (se crioulos ou africanos). Mais uma vez, o lugar social do senhor (o que pode incluir até a vizinhança) representaria um bom indicativo das chances de casamentos estáveis para os cativos.

Senhores mais ricos também detinham maior quantidade de escravos especializados do ponto de vista ocupacional, tais como carpinteiros, ferreiros e demais. Além disso, alforriavam menos os seus cativos, que fugiam mais. Mas a causalidade está longe de ser mecânica e enseja reflexóes. Uma vez que escravos de senhores mais abastados eram também os que mais se casavam pela Igreja, os que desfrutavam de maior estabilidade familiar, os mais especializados (logo, também os mais valorizados) e, em princípio, menos passíveis de sofrer puniçôes, que interesse teriam em pugnar pela liberdade a qualquer custo? Não desfrutavam de maior segurança frente à existência, inclusive para manter suas conquistas intracativeiros, perto de seus senhores? É portanto plausível que os prófugos estivessem situados na base da pirâmide escrava. O leitor atento tirará suas próprias conclusóes. Uma delas: a busca de melhores condições de existência poderia preceder a procura pela manumissão. Outra: era enorme a quantidade de combinaçóes sociais existentes entre o cativeiro e a liberdade. Observa-se, por isso, que um dos maiores méritos de The hierarchies reside justamente no fato de não tomar o conjunto dos escravos nem como uma massa amorfa e nem como um conjunto uniforme de seres humanos, guiados pelos 
mesmos anseios, amalgamados que estavam pela mesma condição jurídica. Ao invés, o autor ressalta o fato de que eles ocupavam diferentes posiçóes sociais, e a compreensão de suas escolhas e atitudes dependia em grande medida da adequada apreensão destas posições pelo pesquisador.

Afora os aspectos metodológicos, a obra de Ian Read revela saborosas curiosidades. Ao longo da análise de como se processava o tráfico de escravos, o autor destaca que um dos principais participantes do "infame comércio" era justamente o cônsul inglês, John Hayden. Agindo cartorialmente sob o nome de sua esposa, Hayden - que teve por padrinho de seu filho ninguém menos do que o baráo de Mauá - acaba por desvelar que a força da escravidáo como instituição aceita durante quase todo o período de sua vigência transformava rapidamente outsiders - no caso, o representante de um país que combatia a instituição - em senhores ou comerciantes de escravos. Do mesmo modo, chama atençáo o fato de que, em plena década de 1870, quando o cativeiro encaminhava-se para o seu final, existiam libertos comprando escravos.

Santos certamente compartilhava várias outras características com localidades brasileiras. Inclusive o fato de que, quando a cidade se auto- declarou livre da escravidáo, na década de 1880, habitavam-na ainda muitos libertandos (aqueles que eram alforriados de maneira condicional). Mas se o quilombo Jabaquara singularizava o município nas últimas décadas da escravidão — Read postula que, em certo momento, o Jabaquara chegou a ter cerca de 10 mil residentes, provenientes de diversas áreas —, esperava-se que o autor desse maior atenção a esses prófugos.

Outros problemas? Quem vive em evidência chama a atenção do Destino, insiste um provérbio chinês. Por isso, o fato de The hierarchies ter sido escrito para um público norte-americano, obviamente pouco afeito à história e historiografia sobre a escravidão no Brasil, torna algo cansativa a descrição da produção de algumas fontes. Pensando melhor, tal procedimento demonstra a preocupação do autor com a sistemática crítica interna e externa dos documentos, como a importante ponderação de que certas listas nominativas não servem para averiguar se as pessoas viviam no meio urbano ou rural, por exemplo. Ao final, remanesce a sensação de que The hierarchies representa uma excelente contribuição para compreendermos a complexidade da escravidão brasileira oitocentista para além de paixóes políticas contemporâneas. 